\title{
Very small embryonic-like stem-cell optimization of isolation protocols: an update of molecular signatures and a review of current in vivo applications
}

\author{
Dong-Myung Shin ${ }^{1}$, Malwina Suszynska ${ }^{2}$, Kasia Mierzejewska², Janina Ratajczak ${ }^{2}$ and Mariusz Z Ratajczak ${ }^{2}$ \\ As the theory of stem cell plasticity was first proposed, we have explored an alternative hypothesis for this phenomenon: namely \\ that adult bone marrow (BM) and umbilical cord blood (UCB) contain more developmentally primitive cells than hematopoietic \\ stem cells (HSCs). In support of this notion, using multiparameter sorting we were able to isolate small Sca ${ }^{+} \mathrm{Lin}^{-} \mathrm{CD} 45^{-}$ \\ cells and $\mathrm{CD} 133^{+} \mathrm{Lin}^{-} \mathrm{CD} 45^{-}$cells from murine BM and human UCB, respectively, which were further enriched for the \\ detection of various early developmental markers such as the SSEA antigen on the surface and the Oct4 and Nanog \\ transcription factors in the nucleus. Similar populations of cells have been found in various organs by our team and others, \\ including the heart, brain and gonads. Owing to their primitive cellular features, such as the high nuclear/cytoplasm ratio and \\ the presence of euchromatin, they are called very small embryonic-like stem cells (VSELs). In the appropriate in vivo models, \\ VSELs differentiate into long-term repopulating HSCs, mesenchymal stem cells (MSCs), lung epithelial cells, cardiomyocytes \\ and gametes. In this review, we discuss the most recent data from our laboratory and other groups regarding the optimal \\ isolation procedures and describe the updated molecular characteristics of VSELs. \\ Experimental \& Molecular Medicine (2013) 45, e56; doi:10.1038/emm.2013.117; published online 15 November 2013
}

Keywords: VSEL; Igf2-H19 locus; Oct4; Sall4

\section{INTRODUCTION}

The field of regenerative medicine is currently searching for a reliable source of pluripotent stem cells (PSCs) that could give rise to cells from all three germ layers. ${ }^{1}$ For almost 20 years, researchers have been attempting to harness embryonic stem cells (ESCs) that can be isolated from the embryos generated by in vitro fertilization ${ }^{2,3}$ or therapeutic cloning. ${ }^{4}$ However, this strategy is burdened by ethical considerations. A promising source of PSCs can be generated by the genetic modification of adult tissues — induced PSCs $s^{5,6}$ — but this strategy is still under development and risks the formation of teratomas in the injected cells, in addition to rejection by the host immune system. ${ }^{7}$

Various potential types of adult stem and progenitor cells can now be isolated from bone marrow (BM), mobilized peripheral blood and umbilical cord blood (UCB) or derived from expanded in vitro cultures of adherent cells (such as mesenchymal stem cells (MSCs) and multipotent adult progenitor cells (MAPCs)) and are being investigated in clinical trials to determine their ability to regenerate damaged organs (for example, heart, kidney and neural tissues). ${ }^{8}$ Rare cases of chimerism after the infusion of unmanipulated donor $\mathrm{BM}, \mathrm{UCB}$ or mobilized peripheral blood cells have been reported by some investigators; however, these results can be explained by cell fusion ${ }^{9,10}$ or presence of rare populations of stem cells that are endowed with multi-tissue differentiation abilities. $^{8}$

Thus, two of the most intriguing questions in stem cell biology are (1) if adult tissues contain PSCs or multipotent stem cells and (2) if these cells can differentiate into cells from more than one germ layer. Several groups of investigators have employed various isolation protocols, surface marker detection systems and experimental in vitro and in vivo models and have reported the presence of cells that possess pluripotent/multipotent characteristics in various adult organs. Such cells have been assigned various operational abbreviations and names in

\footnotetext{
${ }^{1}$ Department of Biomedical Sciences, University of Ulsan College of Medicine, Seoul, Korea and ${ }^{2}$ Stem Cell Institute at James Graham Brown Cancer Center, University of Louisville, Louisville, KY, USA

Correspondence: Professor MZ Ratajczak, Stem Cell Institute at James Graham Brown Cancer Center, University of Louisville, 500 South Floyd Street, Room 107, Louisville, KY 40202, USA.

E-mail: mzrata01@louisville.edu
}

Received 11 July 2013; accepted 22 July 2013 
the literature, such as MAPCs, ${ }^{11}$ multipotent adult stem cells (MASCs), ${ }^{12,13}$ unrestricted somatic stem cells, ${ }^{14}$ marrowisolated adult multilineage-inducible cells ${ }^{15}$ and multilineagedifferentiating stress-enduring stem (Muse) cells. ${ }^{16}$ However, this raises the basic question: are these truly distinct cells or instead just overlapping populations of the same primitive stem cell? In fact, taking into consideration the common features described in the literature, it is very likely that various investigators have described overlapping populations of developmentally early stem cells that are closely related. Unfortunately, these cells were never characterized side-by-side in order to address this important issue. Moreover, the rare and quiescent population of so-called very small embryoniclike stem cells (VSELs), which was initially isolated from murine tissues and human UCB by our group ${ }^{17,18}$ (and subsequently confirmed by other laboratories ${ }^{19-23}$ ), expresses several PSC markers and, in addition, shares some characteristics with the abovementioned cell populations.

VSELs circulate in PB under steady-state conditions; however, the number of cells is very low. In our recent study, we provide evidence that VSELs can mobilize into PB in mice and adult patients who have been injected with granulocyte colony-stimulating factor. ${ }^{24}$ This observation laid the foundation for the concept that granulocyte colonystimulating factor mobilization can be employed to harvest VSELs from patients for therapeutic purposes. Furthermore, our studies on VSEL mobilization into PB reveal that VSELs are mobilized not only in patients suffering from myocardial infarct ${ }^{25}$ and stroke ${ }^{26}$ but also in patients suffering from skin burns, ${ }^{27}$ active inflammatory bowel disease ${ }^{28}$ and cancer. ${ }^{29}$ In a recently published paper, Taichman et al. ${ }^{19}$ demonstrated that VSELs circulating in PB in tumor-bearing mice may give rise to tumor-associated fibroblasts involved in tumor expansion. ${ }^{29}$ More importantly, based on our preliminary data, we also believe that the number of VSELs circulating in PB could be prognostic of myocardial infarct or stroke. ${ }^{25,26}$ This notion, however, requires further study and long-term clinical confirmation.

In this article, we discuss the most recent data from our laboratory and others on the optimization of VSEL isolation from adult tissues, provide an update on the molecular characteristics of VSELs, and describe the potential roles of these rare cells in regenerative medicine.

\section{THE PRESENCE OF POTENTIAL PLURIPOTENT STEM CELLS IN ADULT TISSUES}

For many years, it has been accepted that adult tissues contain only tissue-committed stem cells (TCSCs), such as epidermal, hematopoietic or skeletal muscle stem cells, which demonstrate a limited, single, lineage-restricted potential for differentiation. However, recent evidence demonstrates that BM-isolated cells may possess broader differentiation potentials than the hematopoietic stem cells (HSCs) or MSCs present in this tissue. ${ }^{8}$ If we exclude the possibility of stem cell plasticity and HSC transdifferentiation, one has to consider the possibility that BM contains other, more primitive populations of
PSCs and multipotent stem cells that are deposited in BM during embryogenesis.

Accordingly, we consider two scenarios that could occur during early embryogenesis and the development of lineagerestricted TCSCs. ${ }^{1}$ In the first scenario, PSCs develop in the inner cell mass of the blastocyst, or later on in the epiblast, and after giving rise to more differentiated lineage-restricted TCSCs gradually disappear in the developing tissues. In contrast, in the second scenario-which we believe is more likely_-some PSCs giving rise to TCSCs survive in developing adult tissues as a backup population of PSCs that renews the pool of TCSCs over time. In this scenario, PSCs are not only precursors of TCSCs during organ/tissue rejuvenation but also serve as a source of PSCs during emergency situations when these organs are damaged (for example, myocardial infarction and stroke). This scenario, however, requires the PSC population in adult tissues to be kept under control and in a quiescent state essential for preventing uncontrolled proliferation that could lead to the formation of teratomas. We believe that VSELs are a population of such cells, and the mechanism that keeps them quiescent in adult tissues is similar to the one described in migrating primordial germ cells (PGCs). This mechanism requires the epigenetic modification of the regulatory regions of some developmentally crucial genes that are, themselves, regulated by parental imprinting. ${ }^{30}$

Our recent research revealed that murine VSELs modulate the expression of parentally imprinted genes (for example, Igf2-H19, RasGRF1 and Igf2R (insulin-like growth factor receptor 2)) via epigenetic changes, which may have an important role in insulin/insulin-like growth factor signaling (IIS).$^{31}$ It is well known that imprinted genes have a crucial role in embryogenesis, fetal growth, the totipotential state of the zygote, and the pluripotency of developmentally early stem cells. ${ }^{32}$ Thus, modification of imprinting within the regulatory regions (that is, differentially methylated regions; DMRs) of these genes, which occurs in VSELs, is crucial for maintaining quiescence in the pools of these cells residing in adult tissues. ${ }^{31,33}$ Accordingly, we observed that murine BM-sorted VSELs erase paternally methylated imprints within the DMRs of Igf2-H19 and RasGrf1, whereas they hypermethylate the maternally methylated DMRs of Igf2R and KCNQ1-p5 $7^{K I P 2}$. As paternally expressed imprinted genes (Igf2 and RasGrf1) enhance embryonic growth and maternally expressed genes (H19, Igf2R and $p 57^{K I P 2}$ ) inhibit cell proliferation, ${ }^{34}$ the unique genomic imprinting pattern observed in VSELs represses the growth of these cells. ${ }^{31}$

How do epigenetic changes in gene expression translate into changes in the state of VSELs? In murine VSELs (Figure 1), the abovementioned epigenetic changes lead to perturbation of IIS by downregulating (1) insulin-like growth factor 2 (Igf2), which is an autocrine factor involved in the proliferation of VSELs, and (2) RasGrf1, which is a GTP-exchange factor (GEF) crucial for signaling from activated insulin-like growth factor 1 receptor (IgfIR) and insulin receptor. ${ }^{35}$ In addition, hypermethylation of the DMRs on the maternal chromosome that encode Igf $2 \mathrm{R}$ results in an additional negative effect on IIS 


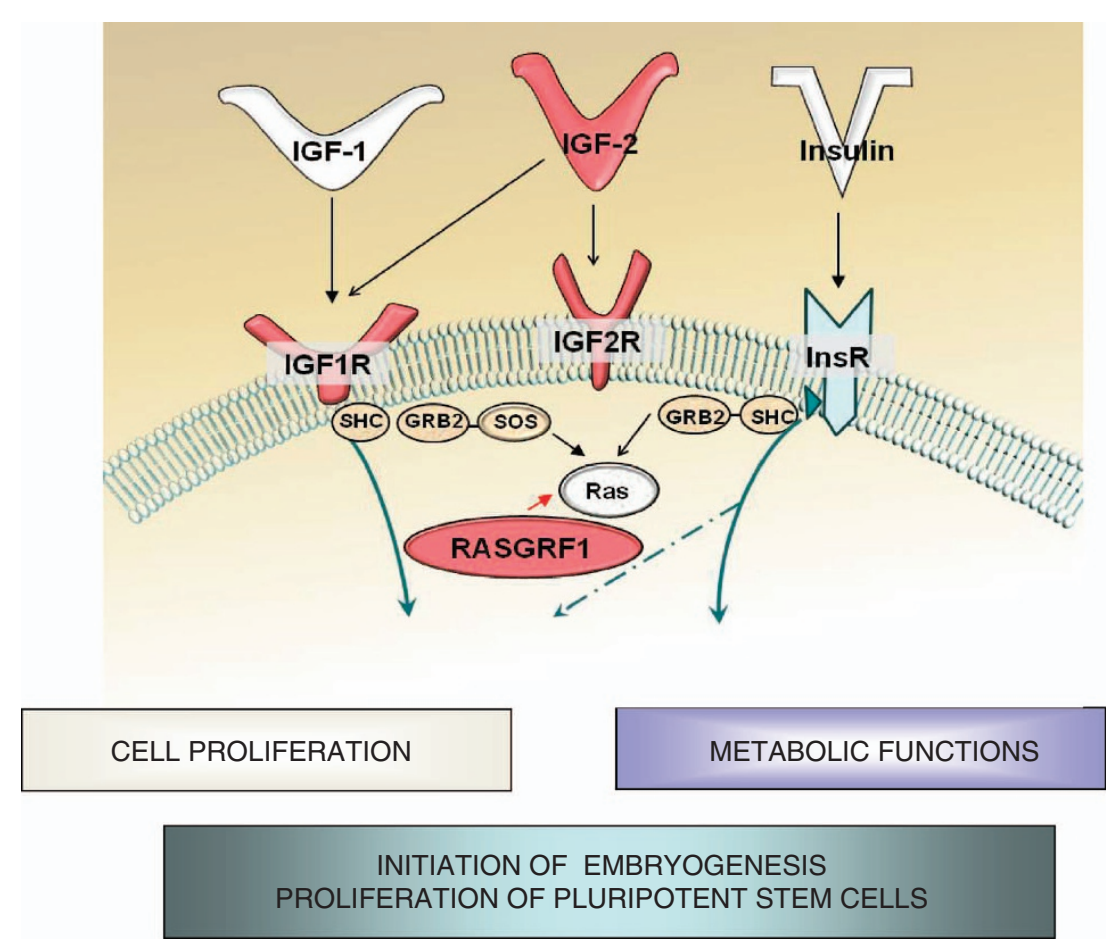

Figure 1 IIS signaling and imprinted genes. In mammals, there are three insulin factors (insulin, Igf1 and Igf2) that bind to two tyrosine kinase receptors (insulin receptor (InsR) and Igf1 receptor (Igf1R)). Igf2R is a non-signaling mannose-type sink receptor for Igf2. Activation of InsR and Igf1R leads to metabolic or proliferative responses depending on the cell type. RasGrf1 is a small GEF that is involved in signaling from InsR and Igf1R. VSELs demonstrate a decrease in Igf2 and RasGrf1 expression and the overexpression of Igf2R (shown in red) due to changes in the epigenetic state of the imprinted genes. These epigenetic changes in genes regulate IIS and maintain quiescence in VSELs in adult tissues that are somehow resistant to in vitro expansion. We hypothesize that chronic exposure to IIS accelerates the premature depletion of VSELs from adult tissues.

in VSELs. As previously described, Igf $2 \mathrm{R}$ serves as a decoy receptor that prevents Igf2 from binding to IgfIR. ${ }^{36}$ This epigenetic reprogramming of genomic imprinting negatively affects IIS signaling, maintains the quiescent state of murine VSELs (Figure 1), and, thus, protects VSELs from premature depletion from the tissues and prevents their involvement in tumor formation. Our most recent unpublished data on the methylation status of DMRs at the Igf2-H19 locus in human VSELs suggest that a similar mechanism may also operate in human VSELs.

Next, based on the published studies reporting that IIS signaling negatively affects the lifespan of experimental animals, ${ }^{37,38}$ we proposed a hypothesis that relates aging, longevity and IIS to the abundance and function of pluripotent VSELs that are present in adult murine tissues. ${ }^{39}$ Accordingly, we postulated that a prolonged IIS may negatively affect the pool of VSELs and, subsequently, TCSCs in various organs, thereby having an impact on tissue rejuvenation and lifespan..$^{33}$ In support of this notion, we reported a significantly higher number of VSELs in BM of long-living murine strains of mice (for example, Laron and Ames dwarfs), whose longevity is explained by low levels of circulating IGF1 and, thus, a decrease in IIS. ${ }^{40}$ In contrast, the number of VSELs is reduced in mice with high levels of circulating Igf1 and enhanced IIS (for example, growth hormone-overexpressing transgenic mice) in comparison with normally aging littermates. ${ }^{41}$

We are currently investigating the influence of calorie restriction and the effects of the prolonged administration of drugs that modulate IIS and extend lifespan, such as metformin and rapamycin, on the pool of VSELs residing in BM and other tissues.

\section{OPTIMIZATION OF ISOLATION STRATEGIES}

VSELs are very rare $\left(\sim 1\right.$ per $10^{5}$ monocular BM cells), and careful follow-up isolation protocols are required to purify these cells. Moreover, more specific markers are needed to isolate these cells. Nevertheless, at this point, the best positive surface markers that allow purification by multisorting analysis are the Scal antigen for murine VSELs and the CD133 antigen for human counterparts. However, these markers are also expressed by several other types of stem cells.

\section{Current strategies for isolating murine VSELs}

The current strategy for purifying murine VSELs from BM, as well as other adult tissues, is based on sorting any nucleated cells that are slightly smaller than erythrocytes $(4-5 \mu \mathrm{m})$ and express the $\mathrm{Scal}^{+} \mathrm{Lin}^{-} \mathrm{CD} 45^{-}$phenotype. These cells also express SSEA1 antigen on their surface, and some VSELs also express receptors for FGF2 (FGF-2R), PDGF (PDGF-R), SDF1 
(CXCR4) and KL (c-kit). We are aware that the lack of specific positive markers for VSELs leads to isolation by cell sorter of rare events that are enriched for VSELs but also contain some cell debris and even bare nuclei. Moreover, when isolating VSELs from murine BM, the most important factor is proper maintenance that consists of a cocktail of lineage antibodies and a sufficient titer against erythroid cells (Ter119) in order to avoid contamination of the sorted VSELs with Lin $^{-} \mathrm{CD} 45^{-}$erythroblasts that may acquire low expression of Scal antigen by microvesicles shed from $\mathrm{Sca}^{+}$cells in BM. Thus, to avoid enrichment of the erythroblasts, it is also important to set up a proper gate that excludes small Sca ${ }^{\mathrm{dim}^{2} \mathrm{Lin}}{ }^{-} \mathrm{CD} 45^{-}$cells, which could become contaminated by erythroblasts.

As mentioned above, some murine VSELs express FGF-2R, PDGF-R, CXCR4 and c-kit on their surface. We still do not know whether this expression of various receptors reflects the commitments of some VSELs to different lineages. In support of this possibility, we recently isolated three different types of mRNA from singly purified VSELs that differ in terms of the expression of pluripotency, germline-specific and various other types of genes. ${ }^{42}$

As murine $\mathrm{BM}$ is a relatively easy tissue for Fluorescenceactivated cell sorting (FACS) analysis and cell sorting, most molecular data are obtained using BM-derived VSELs. However, as there are corresponding populations of cells in other murine solid organs, ${ }^{43}$ further work is needed to compare the molecular signatures of solid organ-purified and BM-isolated VSELs. Similar studies also have to be performed on human VSELs. Nevertheless, in a recent report, an independent group of investigators performed mRNA gene array analysis on human ovarian surface epithelium-derived VSELs and observed similar patterns of expression in genes regulating stem cell pluripotency and germ line specification, ${ }^{44}$ as we described in murine BM-isolated VSELs. ${ }^{17}$ Interestingly, these small human VSELs were efficiently sorted using FACS by employing antibodies against human SSEA4 antigen.

\section{Current strategies for isolating human VSELs}

As described, VSELs from human UCB and mobilized peripheral blood were initially purified as small $\mathrm{CD} 133^{+}$ $\mathrm{CD}_{4} 5^{-}$Lin $^{-}$cells by employing multiparameter sorting from an erythrocyte depleted by hypotonic lysis population of nucleated cells. ${ }^{18}$ Unfortunately, this isolation procedure is time consuming, and the sorting time required to process an entire unit of cord blood ( $\sim 50-100 \mathrm{ml})$, which is needed to isolate rare VSELs from mononucleated UCB cells, would be 3-4 days. Therefore, it has become clear that a faster and less expensive method for isolating these cells must be established. To develop a more efficient method for purifying VSELs from UCB, we proposed a three-step isolation strategy based on (1) removing erythrocytes by hypotonic lysis, (2) immunomagnetic separation of $\mathrm{CD} 33^{+}$cells, and (3) FACS-based isolation of $\mathrm{CD} 133^{+} \mathrm{Lin}^{-} \mathrm{CD} 45^{-}$cells. Processing $100-\mathrm{ml}$ UCB requires only $2-4 \mathrm{~h}$ using this procedure. ${ }^{45,46}$ As with murine VSELs, we do not have a specific marker for VSELs, and our sorted cells may also contain other $\mathrm{CD} 33^{+}$cells. Furthermore, as with murine VSELs, it is very important to employ antihuman erythroid lineage antibodies (CD235a) to avoid contamination with small Lin $^{-} \mathrm{CD} 45^{-}$erythroblasts.

As an alternative strategy, we also attempted exposing erythrocyte-depleted, immunomagnetic bead-selected CD133+ cells to Aldefluor, followed by staining with anti-CD133 antibodies conjugated with fluorochromes and two lineagespecific antibodies-one against pan-hematopoietic antigen CD45 (anti-CD45 MoAbs) and second one against erythroid marker glycophorin-A (anti-GlyA MoAbs). ${ }^{47}$ Aldefluor employed in this alternative sorting strategy is a substrate for aldehyde dehydrogenase (ALDH), a cytosolic enzyme that is highly expressed in less-differentiated hematopoietic cells. In the presence of ALDH, Aldefluor is modified to a fluorescent molecule that maybe used to mark ALDH-expressing cells. Using this novel strategy, we sort $\mathrm{CD}_{133^{+}}$cells enriched for VSELs and obtain from $100 \mathrm{ml}$ of UCB, on average, $\sim 10^{3}$ $\mathrm{CD} 133^{+} \mathrm{CD}_{45}{ }^{-} \mathrm{GlyA}^{-} \mathrm{ALDH}^{\mathrm{low}}$ and $4 \times 10^{3} \mathrm{CD} 133^{+} \mathrm{CD}^{-} 5^{-}$ GlyA $^{-}$ALDH $^{\text {high }}$ VSELs from $100 \mathrm{ml}$ of UCB. ${ }^{47}$ These numbers demonstrate how rare these cells are in UCB. Moreover, when we compared both fractions of VSELs using RT-PCR, we found that $\mathrm{CD} 133^{+} \mathrm{CD}^{-} 5^{-} \mathrm{GlyA}^{-} \mathrm{ALDH}^{\text {low }}$ VSELs demonstrated a higher expression of the pluripotency marker Oct4 than the $\mathrm{CD} 133^{+}{ }^{+} \mathrm{CD} 45^{-}$GlyA $^{-}$ALDH ${ }^{\text {high }}$ fraction. ${ }^{47}$

However, we are aware that there is still room for improvement when it comes to sorting by employing, for example, metabolic fluorochromes to see whether VSELs are enriched among Rh123 dull, Pyronin $Y^{\text {low }}$ and Hoechst $33342^{\text {low }}$ cells. Moreover, we expect our proteomic data analysis of UCBderived VSELs, which is in progress, will reveal the presence of new positive markers that could be employed for sorting these cells. However, as mentioned above, some groups have successfully employed antibodies against SSEA antigens to purify human ${ }^{22}$ and rat VSELs. ${ }^{48}$

Nevertheless, in order to further enrich human VSELs, we recently employed a novel strategy in which we deplete the lineage to thereby enrich CD133 ${ }^{+}$UCB-derived mononuclear cells, which are subsequently permeabilized and stained with anti-Oct4 antibodies. Using this strategy, we isolated a highly purified population of VSELs that was suitable for molecular studies at the DNA (imprinting analysis) and mRNA (gene expression analysis) levels (manuscript in preparation).

\section{THE MOLECULAR SIGNATURE OF VSELS-THE KEY TO UNDERSTAND QUIESCENCE AND PLURIPOTENCY}

As mentioned above, we performed most of our molecular studies on murine BM-purified VSELs at the DNA, mRNA and, to some extent, the protein levels. ${ }^{31,42,49}$ These DNA studies revealed that promoters for pluripotency markers, such as Oct4 and Nanog, have an open chromatin structure and are associated with transcription-promoting histones. ${ }^{31,49}$ This finding strongly supports the authenticity of the expression levels of these pluripotency-regulating transcription factor genes in murine VSELs. Furthermore, as expected from the 
definition of PSC, we reported that VSELs possess so-called bivalent domains in developmentally crucial homeobox genes. ${ }^{42}$ As mentioned above, murine VSELs also possess a unique methylation pattern at the DMRs of some paternally imprinted genes (for example, erasure of imprinting at the Igf2-H19 and RasGrf1 loci and hypermethylation at the Igf2R and KCNQ1 loci) that is responsible for the quiescent state of these cells (Figure 1) and the decrease in IIS. These changes in the expression levels of paternally imprinted genes were subsequently confirmed using mRNA analysis. ${ }^{31}$

Furthermore, our genome-wide analysis of murine BMderived VSELs revealed that the attenuation of mitogenic growth factor signaling pathways also has a crucial role in quiescence and ageing. ${ }^{50}$ Specifically, VSELs downregulate the genes involved in the responses to UV radiation, mRNA processing and mitogenic growth factor signaling (for example, from Igf1 and TRKA receptors involved in the ERK and PI3K pathways). Using leading-edge subset analysis and real-time quantitative PCR assays, we observed that several genes, such as Grb2, Sos1, Shc1, Map2k1, Akt3, Elk1, Rps6ka3, Gsk $3 \beta$ and Csnk2al, which are involved in mitogenic growth factor signaling pathways, are commonly downregulated in VSELs. In contrast, we observed that Oct4 ${ }^{+}$VSELs upregulate tissue-specific gene sets and a gene set that encodes the complement-coagulation cascade.

These results suggest that the epigenetic reprogramming of genomic imprinting maintains the quiescence of the Oct ${ }^{+}$ epiblast/germ line-derived VSELs that are deposited in the adult body and protects them from premature ageing and uncontrolled proliferation. ${ }^{51}$ On the other hand, reversal of this mechanism will be crucial for employing VSELs as a population of PSCs for use in regenerative medicine. Currently, we are investigating how the downregulation of the expression of H19 enhances VSEL expansion, as recently demonstrated in parthenogenesis-derived PSCs. ${ }^{52}$

As briefly mentioned above, our mRNA expression studies revealed that VSELs express several epiblast and germline markers, which is the basis for the hypothesis that VSELs originate from early epiblast-derived migrating PGC-like cells. We envision that VSELs are deposited in adult tissues during development as a source of TCSCs and have a role in organ rejuvenation. In support of this notion, molecular analysis of murine BM-derived VSELs revealed that these cells express several genes that are characteristic of epiblast stem cells such as Gbx2, Fgf5 and Nodal and germline specification of stem cells including Blimp1, Prdm14, Fragilis, Stella, Nanos3 and Dnd $1 .{ }^{49}$ Recently, we also found that both murine and human VSELs highly express Sall4, a marker of germline cells. We also demonstrated that murine and human VSELs (1) are diploid, (2) are viable, as shown by their ability to exclude viability dye (7-aminoactinomycin D), and (3) highly express telomerase. ${ }^{17}$

We are currently assessing the expression of various miRNA species in VSELs, as well as how to perform proteomic analysis on these rare cells. We hope the latter approach will allow us to identify new and unique markers for these cells that will allow optimal and rapid purification.

\section{DATA SUPPORTING THE PRESENCE OF VERY SMALL} STEM CELLS IN ADULT MURINE AND HUMAN TISSUES

As mentioned above, several primitive cells with the characteristics for pluripotency or multipotency were isolated from adult murine and human BM, UCB and adult solid organs, enzymatically processed using proteolytic enzymes, and expanded and cultured in vitro. ${ }^{14,53-56}$ From these cultures, in which the cells were allowed to grow and adhere to plastic or fibronectin, several populations of primitive cells were isolated, expanded and assigned different operational names such as MAPCs, MASCs, marrow-isolated adult multilineage-inducible cells, Muse cells or unrestricted somatic stem cells. ${ }^{11-16,57}$ Unfortunately, the phenotype of the stem cell that initiated these cultures has never been clearly described. Furthermore, very small cells, which are most likely human VSELs, can also be directly purified from neonatal UCB. ${ }^{22,58}$ In addition to multiparameter sorting, other isolation strategies have been employed, and, for example, an interesting population of small cells that is able to differentiate into epithelial and HSCs was isolated from murine BM by elutriation, lineage depletion and the ability to home $(\mathrm{H})$ to $\mathrm{BM}$, has been described as ELH stem cells. ${ }^{59-61}$ Another group reported presence in adult mammalian tissues of small cells, which are able to differentiate into cells from all germ layers and have been isolated from adult mammalian tissues (known as 'spore-like stem cells'). However, the purification strategy and expressed surface markers were not described in the original report. ${ }^{62}$ Nevertheless, the presence of ELH stem cells and 'spore-like stem cells' residing in adult $\mathrm{BM}$ has somehow challenged the concept of HSC plasticity.

The most common features of VSELs are their very primitive morphology and relatively small size. ${ }^{17,18}$ Recently, several reports were published that support the existence of small, primitive VSELs and VSEL-like cells in adult tissues (the most important are listed in Table 1). In addition to ELH cells and the spore-like stem cells mentioned above, VSELs or VSEL-like stem cells have been isolated by other independent groups. For example, murine BM-derived VSELs have been shown to give rise to type 2 pneumocytes, which produce lung surfactant protein after being transplanted into surfactantdeficient mice. ${ }^{21}$ Furthermore, small $\mathrm{Oct} 4^{+} \mathrm{SSEA}^{+} \mathrm{Lin}^{-}$ $\mathrm{CD}_{4}{ }^{-}$cells isolated from rat $\mathrm{BM}$ gave rise in vivo to cardiomyocytes and endothelial cells in an experimental model of rodent acute myocardial infarction. ${ }^{48}$ Moreover, cells from human-mobilized $\mathrm{PB}$ expressing the SSEA4 ${ }^{+}$ $\mathrm{CD}_{133}{ }^{+} \mathrm{CXCR}^{+}{ }^{+} \mathrm{Lin}^{-}$and $\mathrm{CD} 45^{-}$phenotypes that were isolated using FACS formed human bones when embedded in gelatin sponges and implanted into immunodeficient mice; this bone-forming activity exceeded the activity of the other populations of BM-purified cells that were evaluated using the same assay. Based on this finding, it has been proposed that these PB-purified VSELs are at the top of the hierarchy for the mesenchymal and endothelial lineages. ${ }^{23}$ Cells similar to BM-derived VSELs have been reported to reside in the ovarian surface epithelium in postmenopausal ovaries ${ }^{63}$ and normal testes $^{64}$ and differentiate into gametes. ${ }^{44}$ Furthermore, human 
Table 1 Summary of the findings from a selection of reports on stem cells that are attributable to VSELs or closely related cells

Cells originally

named in the paper

Isolation procedure and properties described in the original paper

Reference

ELH cells

Isolated by elutriation, lineage depletion and recovery after homing $(\mathrm{H})$ to the $\mathrm{BM}$. Differentiate to

$59-61$

Spore-like stem cells epithelial cells and hematopoietic cells.

Small nonhematopoietic Small, $\sim 5 \mu \mathrm{m}$ in diameter, isolated from various murine tissues, resistant to freeze/thawing, express Oct4 and demonstrating broad differentiation. Isolation procedures not indicated.

Sca1 ${ }^{+} \mathrm{Lin}^{-}{ }^{-} \mathrm{CD} 45^{-}$cells Isolated using FACS from murine BM, differentiate into type II pneumocytes, produce surfactant in the lung alveolar epithelium. Recently these cells were confirmed as VSELs.

Rat VSELS

Isolated using FACS from rat bone marrow as SSEA ${ }^{+} \mathrm{Lin}^{-} \mathrm{CD} 45^{-}$cells and endowed with cardiomyogenic and endothelial potential.

Human PB-derived VSELS Isolated using FACS as SSEA4 ${ }^{+} \mathrm{CD} 133{ }^{+} \mathrm{CXCR}^{+}{ }^{+} \mathrm{Lin}^{-}$and $\mathrm{CD} 45^{-}$cells, described as being at

Ovarian VSELS the top of the mesenchymal lineage hierarchy. Develop into human bones in immunodeficient mice. Small Oct4 ${ }^{+}$SSEA ${ }^{+}$cells were isolated using FACS from ovarian surface epithelium (OSE) obtained from mice and humans (precursors of female gametes). Human OSE-derived VSELs were extensively characterized using mRNA expression array analysis.

Testicular VSELs Small Oct4 ${ }^{+}$SSEA ${ }^{+}$cells identified in murine and human testes (precursors of male gametes). Small CD45-/CD33-/CD7-/CD235a- pluripotent stem cells (2-3 $\mu \mathrm{m}$ in diameter) coexpressing Embryonic-like stem cells from UCB Omnicytes embryonic stem cell markers, including Oct4 and Sox2, able to differentiate into neuronal cells. Small Oct4 ${ }^{+}$stem cells identified in UCB, able to establish fetal-maternal chimerism.

Abbreviations: BM, bone marrow; FACS, 5 Fluorescence-activated cell sorting; UCB, umbilical cord blood; VSEL, very small embryonic-like stem cell.

PB-VSELs have been successfully purified by other researchers, ${ }^{23,65}$ and very small Oct $4^{+}$Sox $2^{+}$cells corresponding to UCB-derived VSELs described by us were purified from UCB by other investigators, who described them as a population of UCB-derived embryonic-like stem cells. ${ }^{58}$ Interestingly, these cells were able to differentiate in vitro into neural progenitor cells. Finally, a corresponding population of primitive Oct ${ }^{+}$stem cells that resembles VSELs—named omnicytes-was also described to be circulating in UCB and was capable of migrating into the maternal circulatory system. ${ }^{66}$

In addition to the cells listed in Table 1, in one of recent reports small cells with some of VSEL markers have also been identified in murine neonatal retina. ${ }^{67}$ In another study, small nonhematopoietic lineage-negative $\left(\mathrm{Lin}^{-}\right)$cells that have been isolated from adult BM by elutriation (Fraction 25 or Fr25) were involved in retinal regeneration following the induction of anterior ischemic optic neuropathy and optic nerve crush injury in a rodent model. ${ }^{68}$ Moreover, a similar population of small nonhematopoietic $\mathrm{CD}^{-} 5^{-}$stem cells harvested from BM via elutriation was recently shown to differentiate in vivo into functional insulin-producing cells in chemically induced diabetic mice. ${ }^{69}$ Finally, several features of VSELs are present in Muse cells that were recently isolated from murine and human BM populations. ${ }^{16,57}$ As postulated by the authors, Muse cells may have a major role in populations of cells that preferentially become transformed and give rise to immortal induced PSCs when BM-derived stromal cells are induced to pluripotency by genetic manipulation. Thus, VSELs and VSELresembling cells are currently purified in several laboratories worldwide, and the coming years will bring more information
Table 2 In vitro and in vivo criteria for pluripotent stem cells

VSELS

In vitro criteria for PSCS

Undifferentiated morphology, euchromatin and high

nucleus/cytoplasm ratio

PSC markers (for example, Oct4, Nanog, SSEA), open

Yes

chromatin at the Oct4 promoter, bivalent domains and

Yes

reactivation of the $X$ chromosome in female PSCs

Broad multilineage differentiation into cells from all

Yes

three germ layers (meso-, ecto- and endoderm)

In vivo criteria for PSCs

Complement blastocyst development

Teratoma formation after inoculation into immunodeficient

No

mice

Abbreviations: PSC, pluripotent stem cell; VSEL, very small embryonic-like stem cell.

regarding their biology and in vitro and in vivo differentiation potential.

\section{IN VITRO AND IN VIVO CRITERIA FOR STEM CELL PLURIPOTENTIALITY—COMPARISON WITH VSELS}

Several criteria have been proposed for classifying stem cell as PSCs (Table 2). These criteria were established by embryologists working on ESCs and induced PSCs. However, some of these stringent criteria of pluripotency listed in (Table 2), such as complementing blastocyst development and teratoma formation, are not always applicable for pluripotent epiblast stem cells (EpiSCs) as well as PGCs. ${ }^{70,71}$ 
Our experimental data support that murine VSELs fulfill all the in vitro criteria listed in Table 2. In particular, as discussed in this review, murine VSELs not only possess the primitive morphology of early developmental cells (for example, high nuclear/cytoplasmic ratio, presence of euchromatin in the nucleus) but also express the marker characteristics for PSCs (for example, Oct4, Nanog, Rex1). Significantly, we recently confirmed the authentic expression of Oct4 in murine VSELs by demonstrating that the Oct4 promoter have an open chromatin by direct analysis of methylation state (hypomethylation in DNA) and its high association with transcriptionfavorable histone modifications (for example, the acetylation of histone $\mathrm{H} 3$ and trimethylation of lysine 4 on histone 3 ) and relatively low association with the transcription-restricting ones (for example, dimethylation of lysine 9 on histone 3 ). ${ }^{31}$ We also studied the epigenetic state of another pluripotencyrelated transcription factor, Nanog. In comparison to Oct4, the promoter of Nanog has a higher level of methylation in VSELs $(\sim 50 \%)$, and the quantitative chromatin immunoprecipitation experiments performed in parallel revealed that the $\mathrm{H} 3 \mathrm{Ac} / \mathrm{H} 3 \mathrm{~K} 9 \mathrm{me} 2$ ratio favors transcription and maintains its active state. ${ }^{72-74}$ Based on these results, we conclude that murine VSELs truly express both Oct4 and Nanog.

In addition, murine VSELs fulfill also other in vitro criteria of pluripotency (Table 2) such as presence of bivalent domains in promoters that encode developmentally important homeobox-containing transcription factors (Sox21, Nkx2.2, Dlx1, Lbx1h, Hlxb9, Pax5 and HoxA3) $)^{42}$ and VSELs derived from female mice reactivate the $\mathrm{X}$ chromosome. Finally, we and other groups have successfully differentiated VSELs in vitro into cells from all three germ layers. Accordingly, recently published studies confirm that murine BM-derived VSELs can differentiate in vivo into $\mathrm{HSCs},{ }^{47} \mathrm{MSCs},{ }^{19}$ endothelial cells, ${ }^{48}$ epithelial cells of the lung, ${ }^{21}$ oocytes, ${ }^{44}$ tumor stroma cells ${ }^{29}$ and cardiomyocytes. ${ }^{20}$

However, murine VSELs do not complete blastocyst development and do not develop teratomas, which are included in the in vivo criteria of PSCs (Table 2). This obvious discrepancy between the in vitro and in vivo PSC criteria for VSELs was recently explained by the effects of epigenetic changes in the expression of some paternally imprinted genes, ${ }^{31}$ as described above. Moreover, one has to take into consideration that, although all these in vivo criteria apply very well for ESCs and iPSc, they are not always applicable as mentioned above for EpiSCs and PGCs.

\section{CONCLUSIONS}

New data from our and other independent laboratories have provided more convincing evidence for the existence and biological role of VSELs in murine adult tissues and their potential roles in (1) tissue organ rejuvenation, (2) regulation of lifespan, and (3) the regeneration/repair of damaged organs. We have to emphasize that, although the molecular nature of murine BM-derived VSELs has been extensively characterized, more research is needed to better characterize these small cells in humans. If we can confirm that a similar mechanism based on the epigenetic changes in somatic-imprinted genes operates in human VSELs, perhaps the controlled modulation of this imprinting state to produce proper de novo methylation of the regulatory regions in these genes on the maternal and paternal chromosomes could increase the regenerative power of these cells. This would allow for application of VSELs in clinical medicine. Finally, in order to avoid mistakes in isolation of VSELs we recommend for further reading our most recent paper $^{75}$ in which we address in more details potential pitfalls in FACS sorting strategy. We also recommend an excellent recent review on VSELs published by Dr Krause group. ${ }^{76}$

\section{ACKNOWLEDGEMENTS}

This work was supported by a grant from the National Institutes of Health (2R01 DK074720), the European Union's Innovative Economy Operational Programme (POIG.01.01.02-00-109/09-01), and an endowment from Stella and Henry Hoenig that were awarded to MZR, and by a grant from the Asian Institute for Life Sciences, Seoul, Korea (2013-528) and the Korean Health Technology R\&D Project, Ministry of Health \& Welfare, Republic of Korea (A120301) that were awarded to DMS.

1 Ratajczak MZ, Liu R, Ratajczak J, Kucia M, Shin D-M. The role of pluripotent embryonic-like stem cells residing in adult tissues in regeneration and longevity. Differentiation 2011; 81: 153-161.

2 Evans MJ, Kaufman MH. Establishment in culture of pluripotential cells from mouse embryos. Nature 1981; 292: 154-156.

3 Thomson JA, Itskovitz-Eldor J, Shapiro SS, Waknitz MA, Swiergiel JJ, Marshall VS et al. Embryonic stem cell lines derived from human blastocysts. Science 1998; 282: 1145-1147.

4 Tachibana M, Amato P, Sparman M, Gutierrez Nuria M, Tippner-Hedges R, $\mathrm{Ma} \mathrm{H}$ et al. Human embryonic stem cells derived by somatic cell nuclear transfer. Cell 2013; 153: 1228-1238.

5 Takahashi K, Yamanaka S. Induction of pluripotent stem cells from mouse embryonic and adult fibroblast cultures by defined factors. Cell 2006; 126: 663-676.

6 Wernig M, Meissner A, Foreman R, Brambrink T, Ku M, Hochedlinger K et al. In vitro reprogramming of fibroblasts into a pluripotent ES-cell-like state. Nature 2007; 448: 318-324.

7 Zhao T, Zhang Z-N, Rong Z, Xu Y. Immunogenicity of induced pluripotent stem cells. Nature 2011; 474: 212-215.

8 Ratajczak MZ, Machalinski B, Wojakowski W, Ratajczak J, Kucia M. A hypothesis for an embryonic origin of pluripotent Oct-4 + stem cells in adult bone marrow and other tissues. Leukemia 2007; 21: 860-867.

9 Terada N, Hamazaki T, Oka M, Hoki M, Mastalerz DM, Nakano Y et al. Bone marrow cells adopt the phenotype of other cells by spontaneous cell fusion. Nature 2002; 416: 542-545.

10 Ying Q-L, Nichols J, Evans EP, Smith AG. Changing potency by spontaneous fusion. Nature 2002; 416: 545-548.

11 Jiang $Y$, Jahagirdar BN, Reinhardt RL, Schwartz RE, Keene CD, Ortiz-Gonzalez XR et al. Pluripotency of mesenchymal stem cells derived from adult marrow. Nature 2002; 418: 41-49.

12 Pochampally RR, Smith JR, Ylostalo J, Prockop DJ. Serum deprivation of human marrow stromal cells (hMSCs) selects for a subpopulation of early progenitor cells with enhanced expression of OCT-4 and other embryonic genes. Blood 2004; 103: 1647-1652.

13 Beltrami AP, Cesselli D, Bergamin N, Marcon P, Rigo S, Puppato E et al. Multipotent cells can be generated in vitro from several adult human organs (heart, liver, and bone marrow). Blood 2007; 110: 3438-3446.

14 Kögler G, Sensken S, Airey JA, Trapp T, Müschen M, Feldhahn N et al. A new human somatic stem cell from placental cord blood with intrinsic pluripotent differentiation potential. J Exp Med 2004; 200: 123-135.

15 D'Ippolito G, Diabira S, Howard GA, Menei P, Roos BA, Schiller PC. Marrow-isolated adult multilineage inducible (MIAMI) cells, a unique population of postnatal young and old human cells with extensive 
expansion and differentiation potential. J Cell Sci 2004; 117 2971-2981.

16 Kuroda Y, Kitada M, Wakao S, Nishikawa K, Tanimura Y, Makinoshima H et al. Unique multipotent cells in adult human mesenchymal cell populations. Proc Natl Acad Sci USA 2010; 107: 8639-8643.

17 Kucia M, Reca R, Campbell FR, Zuba-Surma E, Majka M, Ratajczak J et al. A population of very small embryonic-like (VSEL) CXCR4 + SSEA-1 + Oct$4+$ stem cells identified in adult bone marrow. Leukemia 2006; 20: 857-869

18 Kucia M, Halasa M, Wysoczynski M, Baskiewicz-Masiuk M, Moldenhawer S, Zuba-Surma E et al. Morphological and molecular characterization of novel population of CXCR4 + SSEA-4 + Oct-4 + very small embryonic-like cells purified from human cord blood - preliminary report. Leukemia 2006; 21 : 297-303.

19 Taichman RS, Wang Z, Shiozawa Y, Jung Y, Song J, Balduino A et al. Prospective identification and skeletal localization of cells capable of multilineage differentiation in vivo. Stem Cells Dev 2010; 19: 1557-1570.

20 Dawn B, Tiwari S, Kucia MJ, Zuba-Surma EK, Guo Y, SanganalMath SK et al. Transplantation of bone marrow-derived very small embryonic-like stem cells attenuates left ventricular dysfunction and remodeling after myocardial infarction. Stem Cells 2008; 26: 1646-1655.

21 Kassmer SH, Jin H, Zhang P-X, Bruscia EM, Heydari K, Lee J-H et al. Very small embryonic-like stem cells from the murine bone marrow differentiate into epithelial cells of the lung. STEM CELLS 2013 (doi:10.1002/ stem.1413).

22 Bhartiya D, Shaikh A, Nagvenkar P, Kasiviswanathan S, Pethe P, Pawani H et al. Very small embryonic-like stem cells with maximum regenerative potential get discarded during cord blood banking and bone marrow processing for autologous stem cell therapy. Stem Cells Dev 2012; 21 $1-6$.

23 Havens AM, Shiozawa Y, Jung Y, Sun H, Wang J, McGee S et al. Human very small embryonic-like cells generate skeletal structures, in vivo. Stem Cells Dev 2013; 22: 622-630.

24 Kucia MJ, Wysoczynski M, Wu W, Zuba-Surma EK, Ratajczak J, Ratajczak MZ. Evidence that very small embryonic-like stem cells are mobilized into peripheral blood. STEM CELLS 2008; 26: 2083-2092.

25 Wojakowski W, Tendera M, Kucia M, Zuba-Surma E, Paczkowska E, Ciosek $\mathrm{J}$ et al. Mobilization of bone marrow-derived oct-4 + ssea-4 + very small embryonic-like stem cells in patients with acute myocardia infarction. J Am Coll Cardiol 2009; 53: 1-9.

26 Paczkowska E, Kucia M, Koziarska D, Halasa M, Safranow K, Masiuk M et al. clinical evidence that very small embryonic-like stem cells are mobilized into peripheral blood in patients after stroke. Stroke 2009; 40 1237-1244

27 Drukała J, Paczkowska E, Kucia M, Młyńska E, Krajewski A, Machaliński B et al. stem cells, including a population of very small embryonic-like stem cells, are mobilized into peripheral blood in patients after skin burn Injury. Stem Cell Rev Rep 2012; 8: 184-194.

28 Marlicz W, Zuba-Surma E, Kucia M, Blogowski W, Starzynska T, Ratajczak MZ. Various types of stem cells, including a population of very small embryonic-like stem cells, are mobilized into peripheral blood in patients with Crohn's disease. Inflamm Bowel Dis 2012; 18: 1711-1722.

29 Jung Y, Kim JK, Shiozawa Y, Wang J, Mishra A, Joseph J et al. Recruitment of mesenchymal stem cells into prostate tumours promotes metastasis. Nat Commun 2013; 4: 1795.

30 Ratajczak M, Shin D-M, Liu R, Marlicz W, Tarnowski M, Ratajczak J et al. Epiblast/germ line hypothesis of cancer development revisited: lesson from the presence of oct-4 + cells in adult tissues. Stem Cell Rev Rep 2010; 6: 307-316

31 Shin DM, Zuba-Surma EK, Wu W, Ratajczak J, Wysoczynski M, Ratajczak MZ et al. Novel epigenetic mechanisms that control pluripotency and quiescence of adult bone marrow-derived Oct4 + very small embryonic-like stem cells. Leukemia 2009; 23: 2042-2051.

32 Reik W, Walter J. Genomic imprinting: parental influence on the genome. Nat Rev Genet 2001; 2: 21-32.

33 Ratajczak MZ, Shin DM, Schneider G, Ratajczak J, Kucia M. Parental imprinting regulates insulin-like growth factor signaling: a Rosetta Stone for understanding the biology of pluripotent stem cells, aging and cancerogenesis. Leukemia 2013; 27: 773-779.

34 Ratajczak MZ, Kucia M, Liu R, Shin DM, Bryndza E, Masternak MM et al. RasGrf1: genomic imprinting, VSELs, and aging. Aging (Albany NY) 2011; 3: 692-697.
35 Font de Mora J, Esteban LM, Burks DJ, Nunez A, Garces C, Garcia-Barrado MJ et al. Ras-GRF1 signaling is required for normal beta-cell development and glucose homeostasis. EMBO J 2003; 22: 3039-3049.

36 Ludwig T, Eggenschwiler J, Fisher P, D'Ercole AJ, Davenport ML, Efstratiadis A. Mouse mutants lacking the type 2 IGF receptor (IGF2R) are rescued from perinatal lethality inlgf2andlgf1rNull backgrounds. Dev Biol 1996; 177: 517-535.

37 Bartke A. Insulin and aging. Cell Cycle 2008; 7: 3338-3343.

38 Piper MDW, Bartke A. Diet and aging. Cell Metabolism 2008; 8: 99-104.

39 Ratajczak MZ, Shin DM, Ratajczak J, Kucia M, Bartke A. A novel insight into aging: are there pluripotent very small embryonic-like stem cells (VSELs) in adult tissues overtime depleted in an Igf-1-dependent manner? Aging (Albany NY) 2010; 2: 875-883

40 Ratajczak J, Shin DM, Wan W, Liu R, Masternak MM, Piotrowska K et al. Higher number of stem cells in the bone marrow of circulating low lgf-1 level Laron dwarf mice[mdash]novel view on Igf-1, stem cells and aging. Leukemia 2011; 25: 729-733.

41 Kucia M, Shin DM, Liu R, Ratajczak J, Bryndza E, Masternak MM et al. Reduced number of VSELs in the bone marrow of growth hormone transgenic mice indicates that chronically elevated Igf 1 level accelerates age-dependent exhaustion of pluripotent stem cell pool: a novel view on aging. Leukemia 2011; 25: 1370-1374.

42 Shin DM, Liu R, Wu W, Waigel SJ, Zacharias W, Ratajczak MZ et al. Globa gene expression analysis of very small embryonic-like stem cells reveals that the Ezh2-dependent bivalent domain mechanism contributes to their pluripotent state. Stem Cells Dev 2012; 21: 1639-1652.

43 Zuba-Surma EK, Kucia M, Wu W, Klich I, Lillard JW Jr, Ratajczak J et al. Very small embryonic-like stem cells are present in adult murine organs: ImageStream-based morphological analysis and distribution studies. Cytometry Part A 2008; 73A: 1116-1127.

44 Parte S, Bhartiya D, Telang J, Daithankar V, Salvi V, Zaveri K et al Detection, characterization, and spontaneous differentiation in vitro of very small embryonic-like putative stem cells in adult mammalian ovary. Stem Cells Dev 2011; 20: 1451-1464.

45 Zuba-Surma EK, Ratajczak MZ. Overview of Very Small Embryonic-Like Stem Cells (VSELs) and Methodology of Their Identification and Isolation by Flow Cytometric Methods. John Wiley \& Sons, Inc., 2010.

46 Ratajczak MZ, Liu R, Marlicz W, Blogowski W, Starzynska T, Wojakowski W et al. Chapter 3-Identification of Very Small Embryonic/Epiblast-Like Stem Cells (VSELs) Circulating in Peripheral Blood During Organ/Tissue Injuries. In: EHAOWT Zbigniew Darzynkiewicz, Donald W (eds) Methods in Cell Biology, voNolume 103. Academic Press, 2011. pp 31-54.

47 Ratajczak J, Zuba-Surma E, Klich I, Liu R, Wysoczynski M, Greco N et al. Hematopoietic differentiation of umbilical cord blood-derived very small embryonic/epiblast-like stem cells. Leukemia 2011; 25: $1278-1285$.

$48 \mathrm{Wu} \mathrm{JH}$, Wang HJ, Tan YZ, Li ZH. Characterization of rat very small embryonic-like stem cells and cardiac repair after cell transplantation for myocardial infarction. Stem Cells Dev 2012; 21: 1367-1379.

49 Shin DM, Liu R, Klich I, Wu W, Ratajczak J, Kucia M et al. Molecular signature of adult bone marrow-purified very small embryonic-like stem cells supports their developmental epiblast/germ line origin. Leukemia 2010; 24: 1450-1461.

50 Mierzejewska K, Heo J, Kang JW, Kang H, Ratajczak J, Ratajczak MZ et al. Genome-wide analysis of murine bone marrowderived very small embryonic-like stem cells reveals that mitogenic growth factor signaling pathways play a crucial role in the quiescence and ageing of these cells. Int $\mathrm{J} \mathrm{Mol}$ Med 2013; 32: 281-290.

51 Shin DM, Kucia M, Ratajczak MZ. Nuclear and chromatin reorganization during cell senescence and aging - a mini-review. Gerontology 2011; 57: 76-84.

52 Ragina NP, Schlosser K, Knott JG, Senagore PK, Swiatek PJ, Chang EA et al. Downregulation of $\mathrm{H} 19$ improves the differentiation potential of mouse parthenogenetic embryonic stem cells. Stem Cells Dev 2012; 21: 1134-1144.

53 Asahara T, Murohara T, Sullivan A, Silver M, van der Zee R, Li T et al. Isolation of putative progenitor endothelial cells for angiogenesis. Science 1997; 275: 964-966.

54 Prockop DJ. Marrow Stromal Cells as Stem Cells for Nonhematopoietic Tissues. Science 1997; 276: 71-74.

55 Zuba-Surma EK, Kucia M, Ratajczak J, Ratajczak MZ. 'Small stem cells' in adult tissues: very small embryonic-like stem cells stand up! Cytometry Part A 2009; 75A: 4-13. 
56 McGuckin CP, Forraz N, Baradez MO, Navran S, Zhao J, Urban R et al. Production of stem cells with embryonic characteristics from human umbilical cord blood. Cell Prolif 2005; 38: 245-255.

57 Wakao S, Kitada M, Kuroda Y, Shigemoto T, Matsuse D, Akashi H et al. Multilineage-differentiating stress-enduring (Muse) cells are a primary source of induced pluripotent stem cells in human fibroblasts. Proc Natl Acad Sci USA 2011; 108: 9875-9880.

58 McGuckin C, Jurga M, Ali H, Strbad M, Forraz N. Culture of embryonic-like stem cells from human umbilical cord blood and onward differentiation to neural cells in vitro. Nat Protoc 2008; 3: 1046-1055.

59 Jones R, Collector M, Barber J, Vala M, Fackler M, May W et al. Characterization of mouse lymphohematopoietic stem cells lacking spleen colony-forming activity. Blood 1996; 88: 487-491.

60 Jones RJ, Wagner JE, Celano P, Zicha MS, Sharkis SJ. Separation of pluripotent haematopoietic stem cells from spleen colony-forming cells. Nature 1990; 347: 188-189.

61 Krause DS. Bone marrow-derived cells and stem cells in lung repair. Proc Am Thorac Soc 2008; 5: 323-327.

62 Vacanti MP, Roy A, Cortiella J, Bonassar L, Vacanti CA. Identification and initial characterization of spore-like cells in adult mammals. J Cell Biochem 2001; 80: 455-460.

63 Virant-Klun I, Zech N, Rožman P, Vogler A, Cvjetičanin B, Klemenc P et al. Putative stem cells with an embryonic character isolated from the ovarian surface epithelium of women with no naturally present follicles and oocytes. Differentiation 2008; 76: 843-856.

64 Bhartiya D, Kasiviswanathan S, Unni SK, Pethe P, Dhabalia JV, Patwardhan $\mathrm{S}$ et al. Newer insights into premeiotic development of germ cells in adult human testis using Oct-4 as a stem cell marker. J Histochem Cytochem 2010; 58: 1093-1106.

65 Sovalat H, Scrofani M, Eidenschenk A, Pasquet S, Rimelen V, Hénon P. Identification and isolation from either adult human bone marrow or G-CSF - mobilized peripheral blood of CD34 +/CD133 + /CXCR4 + / Lin CD45 - cells, featuring morphological, molecular, and phenotypic characteristics of very small embryonic-like (VSEL) stem cells. Exp Hematol 2011; 39: 495-505.

66 Mikhail MA, M'Hamdi H, Welsh J, Levičar N, Marley SB, Nicholls JP et al. High frequency of fetal cells within a primitive stem cell population in maternal blood. Hum Reprod 2008; 23: 928-933.

67 Liu Y, Gao L, Zuba-Surma EK, Peng X, Kucia M, Ratajczak MZ et al. Identification of small Sca-1 +, Lin -, CD45 - multipotential cells in the neonatal murine retina. Exp Hematol 2009; 37: 1096-1107.e1.
68 Goldenberg-Cohen N, Avraham-Lubin BC, Sadikov T, Goldstein RS, Askenasy N. Primitive stem cells derived from bone marrow express glial and neuronal markers and support revascularization in injured retina exposed to ischemic and mechanical damage. Stem Cells Dev 2012; 21: 1488-1500.

69 Iskovich S, Goldenberg-Cohen N, Stein J, Yaniv I, Fabian I, Askenasy N. Elutriated stem cells derived from the adult bone marrow differentiate into insulin-producing cells in vivo and reverse chemical diabetes. Stem Cells Dev 2012; 21: 86-96.

70 Brons IGM, Smithers LE, Trotter MWB, Rugg-Gunn P, Sun B, Chuva de Sousa Lopes SM et al. Derivation of pluripotent epiblast stem cells from mammalian embryos. Nature 2007; 448: 191-195.

71 Tesar PJ, Chenoweth JG, Brook FA, Davies TJ, Evans EP, Mack DL et al. New cell lines from mouse epiblast share defining features with human embryonic stem cells. Nature 2007; 448: 196-199.

72 Shin DM, Liu R, Klich I, Ratajczak J, Kucia M, Ratajczak MZ. Molecular characterization of isolated from murine adult tissues very small embryonic/epiblast like stem cells (VSELs). Mol Cell 2010; 29: 533-538.

73 Shin DM, Liu R, Klich I, Wu W, Ratajczak J, Kucia M et al. Molecular signature of adult bone marrow-purified very small embryonic-like stem cells supports their developmental epiblast/germ line origin. Leukemia 2010; 24: 1450-1461.

74 Shin DM, Zuba-Surma EK, Wu W, Ratajczak J, Wysoczynski M, Ratajczak $\mathrm{MZ}$ et al. Novel epigenetic mechanisms that control pluripotency and quiescence of adult bone marrow-derived Oct4 $(+)$ very small embryoniclike stem cells. Leukemia 2009; 23: 2042-2051.

75 Ratajczak MZ, Zuba-Surma E, Wojakowski W, Suszynska M, Mierzejewska $\mathrm{K}$, Liu R et al. Very Small Embryonic Like Stem Cells (VSELs) represent a real challenge in stem cell biology. Recent pros and cons in the midst of a lively debate. Leukemia 2013 (doi:10.1038/leu.2013.255).

76 Kassmer SH, Krause DS. Very small embryonic like stem cells: Biology and function of these potential endogenous pluripotent stem cells in adult tissues. Mol Reprod Dev 2013; 80: 677-690.

(c) (1) This work is licensed under a Creative Commons
Attribution 3.0 Unported License. To view a
copy of this license, visit http://creativecommons.org/
licenses/by/3.0/

